\title{
Enhanced Learning through Blended IC and DCN Strategies in C Programming For Non - Computer Science Students
}

\author{
Dr.R.Rajan Prakash ${ }^{1}$, Dr.S.CharlesRaja ${ }^{1}$,Dr.D.Kavitha ${ }^{1}$,Dr.S.Baskar ${ }^{2}$ \\ ${ }^{1}$ Assistant Professor, Department of EEE, Thiagarajar College of Engineering, Madurai - 625015 \\ ${ }^{2}$ Professor, Department of EEE, Thiagarajar College of Engineering, Madurai - 625015 \\ ${ }^{1}$ r_rajanprakash@tce.edu, charlesrajas@tce.edu,dkavitha@tce.edu, sbeee@tce.edu
}

\begin{abstract}
:
Programming Languages have become one of the core courses even for non-computer science students. The domination of Information Technology markets gives more space job recruitments in software field than in any other core fields in India. However, it is found that, learning $\mathrm{C}$ program for non-computer science students is always a difficult task. In this paper, the education research team of department of electrical and electronics engineering has made an attempt through Inverted Classroom (IC) and Desi Chicken Nourishment (DCN) strategies to create a learning environment for $\mathrm{C}$ programming class of third semester Electrical Engineering students. Various methods are adopted to promote effective implementation of IC for perfect understanding of the course. The DCN based approach shows a steadfast improvement in programming skills of the non-computer science students.
\end{abstract}

Keywords: Inverted Classroom, Desi Chicken Nourishment, programming languages.

\section{Introduction}

The implementation Outcome Based Education (OBE) reformed the Indian Engineering Education System for teaching centred to Learning centred. Many good learning strategies are being adopted by faculty for effective knowledge transfer. The basic issues likes creating learning environment inside classroom, making classroom more interactive, inculcating more activities in classes, handling students with different talents \& potential etc are being studied by adopting innovative methods.

One of the issues identified by the education research team of Department of Electrical \& Electronics Engineering is the challenging task of teaching programming languages for third semester students of the same department. It is identified that the subject leads them to a different phase when compared with other core subject papers.The students find very difficult tounderstand and

\author{
Dr.R.Rajan Prakash \\ Assistant Professor, Department of EEE, Thiagarajar \\ College of Engineering, Madurai - 625015 \\ r_rajanprakash@tce.edu
}

studyalong with other subjects. Again, programming is a skill which should be developed only by practice and not just by studying books. Hence, it demands to adopt a strategy for better understanding of the concepts and sufficient practice sessions to enhance the programming skill of the student.

Inverted Class(IC) is one of the strategies that is being effectively practiced across the world for various courses [1-3]. Research results show that FCs are more effective in knowledge transfer if properly planned. ICs help the faculty and students to conserve class time and use the class time for activities and practices. Hence, it is planned to implement FCs in the class for $\mathrm{C}$ programming. Strategies to evaluate student's sincere and serious participation in FC were also developed by the research team.

Peer learning is proved to be an another effective learning strategy [4]. The proposed Desi Chicken Nourishment (DCN) promotes peer learning under the direction of a mentor in a naturally accommodative environment[5]. DCN is adopted for conducting programming classes and to promote practical implementation of concepts with proper guidance. The implementation of DCN tends to enhance the programming skill of a student.

Studies show that the implementation of well planned IC enhances the learning ability of students and DCN develops a passion for programming among the students. The methods adopted for the implementation of IC and DCN, and results are discussed in detail in this paper. 


\section{Methodology}

\section{a. Inverted Classroom:}

IC approach has been used for years in various disciplines. They propose a model in which students gain first-exposure learning (FEL) prior to class and focus on the processing part of learning in class. IC gives ample time to concentrate on synthesizing, analyzing, problemsolving, etc of the subject [1]. Here the learning materials, text book reading, lecture videos, printable power points etc. are provided to the students through CANVAS learning management system(LMS). The students should come prepared for the class and is ensured by means of various class activities.

IC provides,

- An opportunity to gain first exposure prior to the class.

- A mechanism to analyze the understanding of students

- Possibilities to plan more in class activities and practices.

- An option to concentrate on higher cognitive levels

- A chance for students to earn incentives for class preparations.

However, the biggest challenge for the implementation of IC is to enable the students to come prepare for the class using the materials shared in the CANVAS LMS tool. The following in-class activities are adopted to ensure student preparation for effective class time. Periodical rewards and incentives are given to encourage good participation in class activities. Student participation was evaluated every class and the results are discussed.

\section{i. $\quad$ Mini Lecture:}

One of the students will be asked to give a lecture on the FEL content shared in the CANVAS for the period of 5 to 10 minutes. The student will be rewarded by giving suitable grading. It is seen that all the students are tested by some means so that the average grade received by the student will be added to continuous assessment.

ii. Brain storming:

Brain storming is another effective tool to ensure students preparation in IC. It provides more students to participate and motivates voluntary involvement of students. Average number of students involved in every class was taken. Best presentations are rewarded.

iii. Quiz:

Online quiz is conducted at the beginning of the class based on the FEL content. CANVAS [6] and Quizizz[7] tools are used for online organization. Quiz scores are used for analysis and will be added to student's continuous assessment. iv. Share \& Throw Game:

It's game in which the class is divided into few groups. Each group has their own name. One group will share first few portions of FEL materials and pass it to another group. The other group will continue from where the first group left and they will pass it to next group and so on. The group involvements are noted for analysis.

v. Skits:

Students are formed into groups. Instead of taking mini lecture they are asked to present the learned concept in the form of a skit.

vi. Worksheets:

In complete program are given as worksheets. Students should come prepared after completion. The worksheets are randomly collected and rewarded.

\section{vii. One minute paper:}

It is collected often at the end of the lecture hours. But here the students will write the concept they have learned in a small paper and submit it at the beginning of the class. The paper will be evaluated to understand the effective use of IC among students.

\section{b. DCN Implementation:}

DCN is one of the effective methods of peer learning under a proper mentorship. This method has already been applied by the research team for various core and fundamental papers. Here the entire class was divided into groups. Each group was allotted with a mentor, senior student of the same department. They will develop a Hen - Chick(HC) relationship which enables then real in a friendly and comfortable environment.

DCN develops inter personal skills. It benefits both the team members and the mentor. The programming assignment given to each Chicken team will be completed under the guidance of the team Hen(mentor). The HC team meets at regular intervals and intervals. $\mathrm{C}$ program written by the Chicken teams were evaluated, challenges in writing programs were addressed and doubts were cleared in the meeting. At the end of the course competition was conducted and the best HC team(s) was rewarded.

The structure of the HC team is shown in the Fig.1. Here each Hen will report to the faculty once in a week. Every chicken team will meet with hen frequently minimum twice a week. The frequency of meeting depends of the quality of the group. 


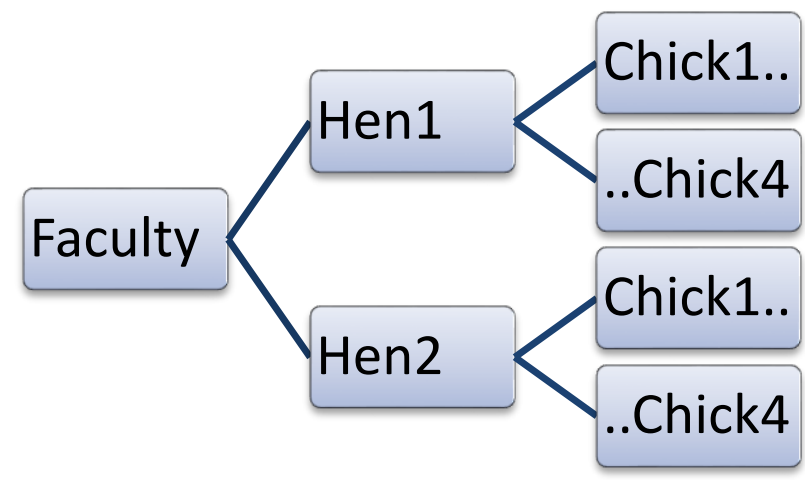

Fig.1 DCN implementation

The success of the DCN depends on the performance of $\mathrm{HC}$ relationship. Here, the Hens will be selected from students of higher semesters. The selection of Chick under the mentorship of each Hen is always a heterogeneous composition. The chick composition is based Q mark which is calculated by $50 \%$ CGPA they have earned and $50 \%$ of performance test conducted before team formation. Based the $\mathrm{Q}$ values obtained the entire class is classified into four category and every $\mathrm{HC}$ team has a student from each category.

The HC team will be given tasks and they will prepare a plan to complete the task. Periodical reviews will be carried out. Students who are found to be very slow even after four weeks will be separated from the $\mathrm{HC}$ pair and a separate HC pair was formed for them to give additional care. Here the tasks were defined as:

i. Understanding basic concepts of $\mathrm{C}$ using simple programs

ii. Writing $\mathrm{C}$ programs using control structures.

iii. Writing $\mathrm{C}$ program using functions and pointers.

iv. Modify one of the above program using arrays \& strings

v. Modify the program in No.4 using structures.

Each $\mathrm{HC}$ team was given freedom to choose and write their own programs. There will be four reviews,

i. At the end of first week

ii. After the completion of Part ii

iii. After completion of part iv

iv. After final completion.

\section{Results and Discussion}

The proposed approach has been implemented in the third semester class of Electrical students.

\section{a. Analysis of IC:}

Many activities are planned to ensure the student preparation for IC. Here some results are given with discussion.

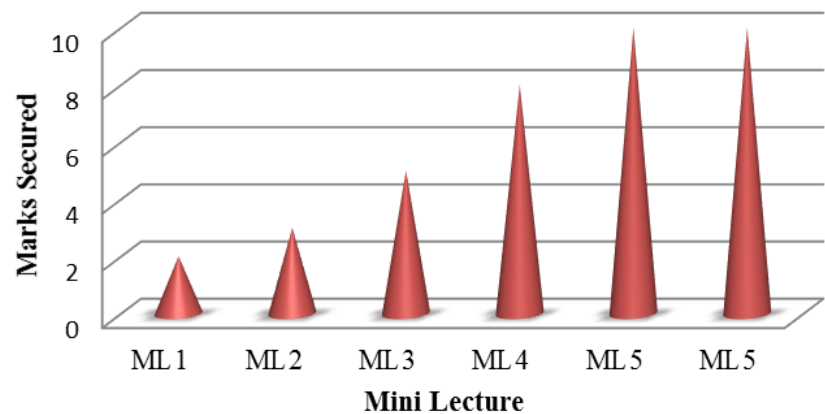

Fig. 2 Mark earned by students in Mini Lecture

Mini Lectures are conducted at times to ensure students participation in IC. Fig 2 represents the progress of students in Mini Lectures. In the first month the average score was less than 2 . At the end of the semester the results shows best performance by the students, which proves the active participation in practicing IC.

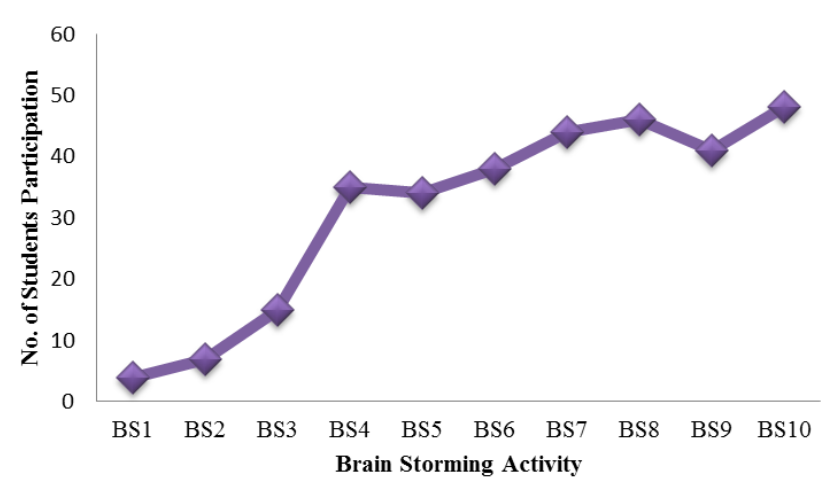

Fig.3 Participation of students in brain storming

The participation of students in brainstorming are shown in Fig3. Brainstorming was based on contents shared earlier before the commencement of class. Best arguments and debates are awarded. This prompts students to involve more and class becomes noisy during brainstorming.

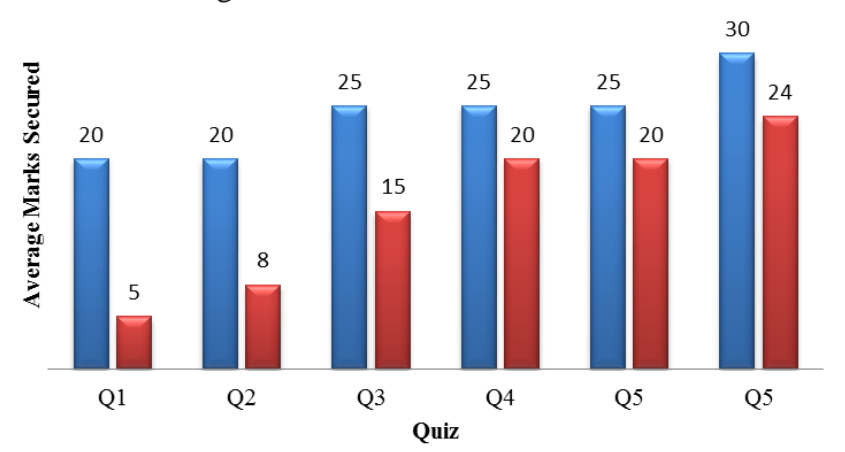

Fig. 4.Average Marks in Quiz

Quizzes were conducted as a part of IC. Online quizzes were conducted using CAVAS or www.quizziz.com. All the times quizzes were conducted either after mini lectures or brainstorming. The graph in Fig.4, shows the maximum marks for each quiz and average marks earned by students in each quiz. It is found that the students performance grows from the beginning to the end of the course. 


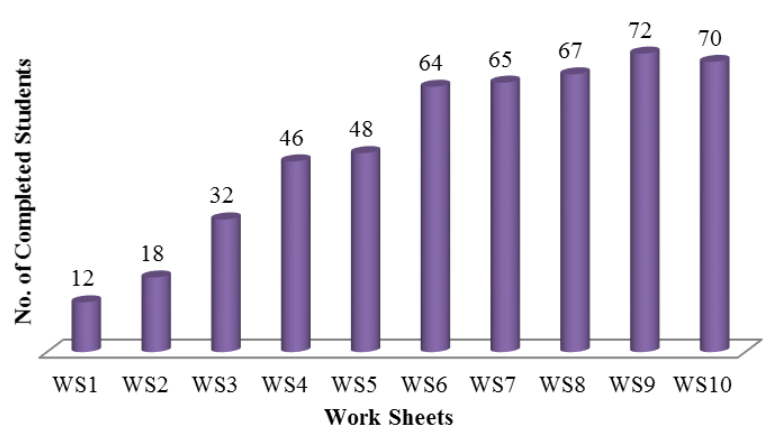

Fig.5 Worksheet completion

Worksheets are effective tools in practicing ICs. In complete programs or programs with errors were given in the class. The students will complete the program or correct the errors. This improves the confidential level and involvement of students and is given as graph in Fig.5.

b. Analysis of DCN:

The analysis of DCN was done based on the practical exam marks and the average marks scored by student in three tests are shown.

It's shown in Fig.6, that the average marks obtained by the students in three practical tests conducted during the course increases significantly. This considerable increase is due to the practice of DCN. Here the students learn from their peer, mentored by their seniors and it promotes self learning. The test performances shows the success of DCN strategy.

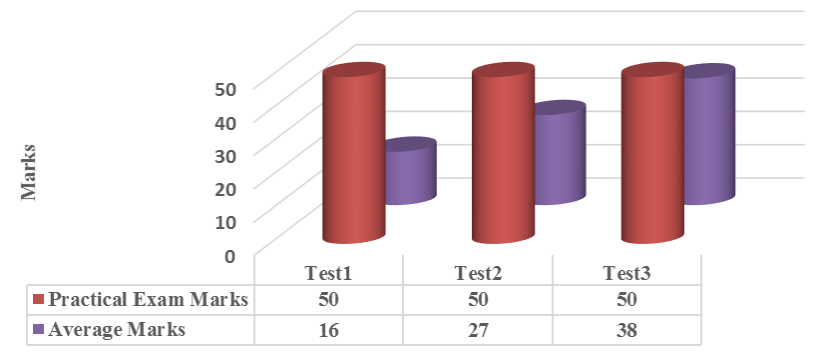

Fig.6 Test Results

c. Discussion:

The results shows,

- Regular increase in the presentation skill of the students in mini lectures for a maximum mark of 10.

- Student's participation in brain storming is increased in class with 75 students.

- Students participation in quiz and worksheet presentation shows significant growth

- DCN strategy promotes programming ability of the students

The above results show the success of the methodology adopted for implementing ICs and DCN strategy. The challenges in implementing were overcome by systematic planning. For example, Students participation in mini lecture was improved by giving rewards and marks regularly. Again, best DCN group contest was conducted to identify and ward the best peer learning team. This promotes the participation of students in the class and creates a learning environment.

\section{Conclusion}

The implementation of blended IC and DCN gives encouraging results. It promotes student participation inside the class. It is noted that interpersonal skill of student is increased. Many timid and reserved students are made to participate in debates and skits which helped them to overcome their weaknesses.

IC helps to concentrate on higher order cognitive level and enhances knowledge in concepts. DCN develops the programming skill of the students and build their confidence. Hence, this approach is found to be effective for learning programming languages like $\mathrm{C}$ and CPP for students other then computer science background.

However, there is still a challenge that further $15 \%$ to $20 \%$ student's involvement is lacking which is another serious concern to be addressed in future.

\section{References}

[1]. https://cft.vanderbilt.edu/guides-sub-pages/flippingthe-classroom/

[2]. AzeemUnissa, AishwaryaGopakumar, Vaishnavi Rao, "Exploring Blended Flipped Classroom for Syllabus Coverage" JEET, Volume 32, Issue 2, October 2018

[3]. Rohini R. Mergu, Shweta U. Bagadi, Vaidehi S. Kulkarni, "Flipped Classroom Strategy to Improve Students' Learning of Computer Communication Network:An Experience Report", JEET, Volume 30, Issue 3, January 2017

[4]. Scott E. Lewis, "Retention and Reform: An Evaluation of Peer-Led Team Learning", J. Chem. Educ.2011, Vol 88, Issue 6,703-707.

[5]. R. Rajan Prakash, S. Charles Raja, D. Kavitha, S. Baskar, "A Paradigm Shift from BCN to DCN Strategy for Effective Knowledge Transfer in Foundation Courses" JEET, Special Issue, 2018

[6]. https://canvas.instructure.com/login/canvas

[7]. https://quizizz.com/

\section{Corresponding Author}

Dr.R. Rajan Prakash, Assistant Professor, EEE, Thiagarajar College of Engineering. 